\title{
The Global Survey of Business Ethics as Field of Training, Teaching and Research: Objectives and Methodology
}

\author{
Gedeon Josua Rossouw
}

Published online: 14 March 2012

(C) Springer Science+Business Media B.V. 2012

\begin{abstract}
This article introduces the Global Survey of Business and Economic Ethics as field of training, teaching and research. For the purpose of the survey the world was divided in nine regions that cover all countries of the world. This special issue of the Journal of Business Ethics presents the findings of the global survey across eight of the nine world regions, viz. Central Asia, East Asia, Europe, Latin America, North America, Oceania, South \& South-East Asia, and Sub-Saharan Africa. This introductory article starts with an overview of previous attempts that were made to survey Business Ethics as field of training, teaching and research on a global scale. A description will then be given of the regions in which the world was divided for the purpose of this survey as well as of the countries included in each of the nine regions. Finally the research process and methods that were used in the survey are introduced.
\end{abstract}

Keywords Business Ethics - Economic Ethics ·

Teaching $\cdot$ Training $\cdot$ Research $\cdot$ Methodology

\section{Introduction}

In 2009 a Global Survey of Business and Economic Ethics as field of training, teaching and research was

An article by the same author was published in a special edition of the African Journal of Business Ethics (5:2, 61-65) in which the Global Survey of Business Ethics was introduced within the Sub-Sahara African context. Consequently there are similarities between that article and this one.

G. J. Rossouw ( $\square)$

University of Pretoria, Pretoria, South Africa

e-mail: deon.rossouw@ethicssa.org commissioned by Globethics.net in Geneva. For the purpose of the survey the world was divided in nine regions that cover all countries of the world. These regions are: (1) Central Asia, (2) East Asia, (3) Europe, (4) Latin America, (5) North America, (6) Oceania, (7) South \& South-East Asia, and (8) Sub-Saharan Africa. The objective of this global survey was to determine how Business and Economic Ethics as a field of training, teaching and research has developed since 1995.

The reason for selecting 1995 as starting date for the survey is because a first attempt to survey the development of Business and Economic Ethics on a worldwide scale was conducted in 1995, first presented at the First ISBEE World Congress in 1996 in Tokyo, and finally published as a special issue of the Journal of Business Ethics in 1997 (cf. Enderle 1997). The 2010 Global Survey of Business Ethics can thus be seen as a follow-up on the previous (1995) survey.

Before the worldwide survey of 1995 a number of studies were published that also surveyed specified aspects of the field of Business Ethics, but none of them was worldwide or global in scope. De George (1987), Van Luijk (1990), and Enderle (1996) published articles that analysed the development of the field of Business Ethics in North America and Europe. Cowton and Dunfee (1995) did a survey that also included Asia, but their survey was merely focused on "internationalizing the business ethics curriculum", and their survey sample was restricted to interviews with 40 persons from Business Schools in the USA, UK and Asia.

Since Enderle's (1997) worldwide survey of Business Ethics, entries on Business Ethics in selected countries were published in The Blackwell Encyclopedic Dictionary of Business Ethics (1997) and in the volume on Business Ethics (vol. 2) in The Blackwell Encyclopedia of 
Management (2005). Recently Chan et al. (2010) published a study that was titled "Business Ethics Research: A Global Perspective". Their study, however, did not have the intention of being a Global Survey of research in the field of Business Ethics. Instead they opted for analysing the publication data of ten leading journals in the field of Business Ethics to identify global patterns in research as well as the leading researchers and research institutions in the field of Business Ethics.

The Global Survey of Business Ethics that will be reported in this special issue of the Journal of Business Ethics thus represents the first attempt to do a truly Global Survey of Business Ethics that includes all countries of the world within its survey scope. The findings of the survey in eight of the nine world regions will be reported. One of the regions, the Middle East \& North Africa region, was not able to produce a regional report (yet). In this introductory article an overview is given of the regions into which the world was divided for the purpose of this survey as well as of the countries included in each of the nine regions. Thereafter the research process and methods that were used in the survey are introduced.

This introduction to the Global Survey of Business Ethics will be followed by eight contributions that consist of regional survey reports of the eight world regions in which the global survey was completed. Finally a concluding article will follow in which a summary and comparative analysis of the findings across the eight world regions will be presented.

\section{Regional Division}

One of the first challenges in doing a global survey of this nature is to decide on how the world should be divided in regions to create regions of manageable proportions for research purposes. A combination of geo-political and researcher availability considerations ultimately resulted in the decision to divide the world in nine regions. Once the nine regions had been decided upon, a number of crucial decisions related to specific countries that border on two or more regions had to be taken. For example, should Mexico be included in North America or in Latin America? Table 1 depicts the final decision that was made regarding the regional and country division for the Global Survey of Business Ethics.

\section{Research Process and Methodology}

The objective of the survey was to determine how Business Ethics as a field of teaching, training and research has developed since 1995 across the world with regard to the following aspects:
- The terminology used to refer to Business and Economic Ethics;

- The prevalence of Business and Economic Ethics;

- The themes covered in training programs on Business and Economic Ethics;

- The themes covered in formal academic teaching on Business and Economic Ethics;

- The themes covered in Business and Economic Ethics research; and

- The major business ethical issues that are foreseen over the next 5 years.

For the purpose of this study a broad definition of Business Ethics as field of training, teaching and research had been agreed upon, which included economic ethics and sustainability (macro-level), corporate responsibility and corporate citizenship (meso-level) and intra-organisational ethics (micro-level). This definition of the field coincides broadly with the definition used for the 1995 worldwide survey of Business Ethics. Enderle (1997, p. 1476) explained with regard to the latter survey that: "Business Ethics is understood in a comprehensive sense that includes issues at the individual, organizational, and systemic levels of decision making in business and economic life."

To conduct the survey a research team was compiled consisting of nine regional coordinators. Each of the regional coordinators had the liberty to compile their own regional research teams. Some of the regional coordinators opted for appointing country representatives for each country in their region, while others compiled sub-regional research teams to cover their region. The names of the regional coordinators and their research teams can be seen in the regional reports that follow on this introductory article.

The research process was divided into 4 stages, which are outlined below:

Stage 1: Identifying individual and institutional expertise in Business Ethics The first task was to identify individuals and institutions with expertise in the field of Business and Economic Ethics in each of the nine world regions. For the purpose of the survey individual expertise was defined as: Persons in the academic environment who spend a substantial amount $25 \%$ or more) of their time on Business and Economic Ethics training or teaching, or who have already published research in Business and Economic Ethics. Institutional expertise in Business Ethics was defined as: Academic, professional and non-profit (but not commercial) associations or institutions with an explicit focus on teaching, training or research in Business and Economic Ethics.

Stage 2: Data collection Once individuals and institutions with expertise in the field of Business and Economic Ethics had been identified they were requested to provide 
Table 1 Regional division of the Global Survey of Business Ethics

Region Countries

1. Central Asia

2. East Asia

3. Europe
Afghanistan

Armenia

Azerbaijan

Georgia

Iran

Kazakhstan

Kyrgyzstan

Mongolia

Russia

Tajikistan

Turkmenistan

Uzbekistan

China

Japan

North Korea

South Korea

Taiwan

Albania

Austria

Belarus

Belgium

Bosnia

Bulgaria

Croatia

Czech Republic

Denmark

Estonia

Finland

France

FYROM (Macedonia)

Germany

Great Britain

Greece

Hungary

Ireland

Italy

Latvia

Lithuania

Moldova

Netherlands

Norway

Poland

Portugal

Romania

Serbia

Slovakia

Slovenia

Spain
Table 1 continued

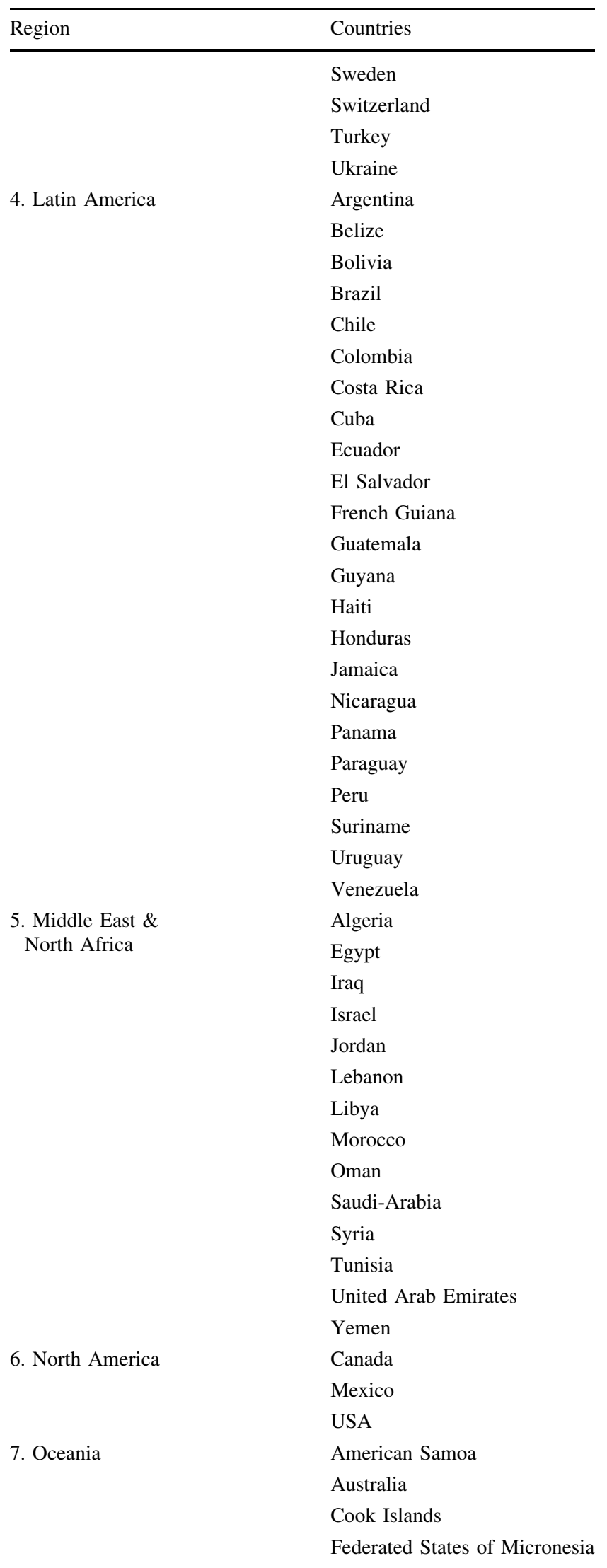


Table 1 continued

\begin{tabular}{ll}
\hline Region & Countries \\
\hline
\end{tabular}

\section{Fiji}

French Polynesia

Futuna Islands

Guam

Indonesia

Kiribati, Nauru

Marshall Islands

New Caledonia

New Zealand

Niue

Norfolk Island

Northern Mariana Islands

Palau

Philippines

Pitcairn

PNG

Samoa

Singapore

Solomon Islands

Timor-Leste

Tokelau

Tonga

Tuvalu

Vanuatu

8. South \&

South-East Asia

9. Sub-Saharan Africa
Wallace

Bangladesh

Bhutan

Burma

Cambodia

India

Laos

Malaysia

Nepal

Pakistan

Sri Lanka

Thailand

Vietnam

Angola

Benin

Botswana

Burquina Faso

Burundi

Cameroun

Central African Republic

Chad

Congo

Djibouti

DRC
Table 1 continued

\begin{tabular}{ll}
\hline Region & Countries \\
\hline & Equatorial Guinea \\
Eritrea \\
Ethiopia \\
Gabon \\
Ghana \\
Guinea \\
Ivory coast \\
Kenya \\
Lesotho \\
Liberia \\
Madagascar \\
Malawi \\
Mali \\
Mauritania \\
Mauritius \\
Mozambique \\
Namibia \\
Niger \\
Nigeria \\
Rwanda \\
Senegal \\
Sierra Leone \\
Somalia \\
South Africa \\
Sudan \\
Swaziland \\
Tanzania \\
Togo \\
Zambia \\
Zimbabwe \\
\\
\hline
\end{tabular}

information on their expertise with regard to Business and Economic Ethics as field of training, teaching and research. For this purpose separate survey questionnaires for individuals and institutions were developed.

In addition to the survey questionnaires the following other methods were used to collect data on individual and institutional expertise in the field of Business Ethics in the respective regions:

- Literature reviews;

- Personal interviews;

- Desktop searches; and

- Database analyses.

Brief descriptions of the above research methods will follow after the description of the various stages of the research process. 
Stage 3: Data collation and processing Once sufficient data had been collected the process of data analysis commenced. Data analysis was done on the data obtained via the survey questionnaires and also via the other methods mentioned above. Through the data analysis categories were identified with regard to:

- The terminology used to refer to Business and Economic Ethics;

- The prevalence and distribution of Business and Economic Ethics;

- The themes covered in training programs on Business and Economic Ethics;

- The themes covered in formal academic courses on Business and Economic Ethics;

- The themes covered in Business and Economic Ethics research; and

- The major economic and business ethical issues that are foreseen over the next 5 years.

Stage 4: Regional reporting The research process culminated in the production of regional reports for each of the world regions. The regional coordinators were responsible for integrating country or sub-regional reports into a comprehensive regional report for their specific region. The broad structure that was followed in each of these regional reports was:

- Existing literature on Business Ethics as field of training, teaching and research in the region;

- Region-specific methodological considerations; and

- Findings regarding the themes of the survey as listed above.

In order to collect the required information about the field of Business and Economic Ethics a number of research methods were used. These include survey questionnaires, literature reviews, personal interviews, desktop searches, and database analyses. Each of these methods is briefly described below:

\section{- Method 1: Survey questionnaires}

Survey questionnaires were designed for both individuals and institutions with expertise in the field of Business and Economic Ethics. After individuals and institutions had been identified who qualified in terms of the respective definitions for individual and institutional expertise in Business and Economic Ethics (see definitions outlined in stage 1 above), they were invited to complete the survey questionnaires. Besides questions dealing with personal or institutional information, the questionnaires consisted of the following questions:

1. What is your native language(s)?

1.1. What terms (concepts/expressions) do you use to refer to Business and Economic Ethics in your native language(s)? Please provide a literal English translation in the case of non-English terms.

2. Please indicate which of the following activities with regard to Business and Economic Ethics you are involved in by ticking the appropriate box(es):

- Training programmes (practical \& vocational training-not for degree purposes)

- Undergraduate teaching

- Postgraduate teaching in Business School or MBA programme

- Postgraduate teaching, but not in Business School or MBA programme

- Research

- Supervision of Masters studies

- Supervision of Doctoral studies

- Consulting/Advisory services for organisations

- Advocacy/Campaigning/Activism

- Policy making

- Any other activity not listed above. Please specify below.

3. Please indicate the topics (themes or issue) related to Business and Economic Ethics that you address in:

3.1. Non-degree earning training programmes

3.2. Undergraduate curricular modules/courses in degree earning programmes. Please indicate an elective module/course with an [E] and a compulsory module/course with a [C].

3.3. Post graduate curricular modules/courses in degree earning programmes. Please indicate an elective module/course with an $[E]$ and a compulsory module/course with a [C].

4. Please list below (or attach as a separate document) all publications on Business and Economic Ethics that you have produced (as author, co-author or editor). In the case of a non-English publication, please provide an English translation of the title of the article, book, or chapter in square brackets.

5. What do you regard as the major ethical issues in the field of Business and Economic Ethics over the next 5 years?

Respondents had the option of completing the questionnaire in one of the following formats:

- Online on the globethics.net website at: http:// www.globethics.net/web/guest/research;

- As a word document (sent as an e-mail attachment); or

- In hard copy.

All the data were collected on a central database and were made available on a regular basis to the regional coordinators. 
As it became clear fairly early in the research process that the response rate to the questionnaires is likely to be low, greater emphasis was placed on the other research methods, and particularly on personal contacts and interviews (face-to-face, telephonically, and electronically) with experts in the field of Business Ethics.

\section{- Method 2: Literature review}

A literature review was done to determine whether any previous studies had been done on Business Ethics as field of either training or teaching or research in the regions, sub-regions or specific countries in each of the regions. The purpose of these literature reviews was to identify previous attempts to reflect on a meta-level on how training, teaching or research on Business and Economic Ethics is approached or institutionalized in a specific region.

\section{- Method 3: Personal interviews}

Personal interviews were conducted with individuals and representatives of institutions with expertise in the field of Business Ethics. These interviews were conducted either face-to-face, electronically via e-mail, or by telephone or skype. The interviews were semi-structured and probed respondents with regard to the same questions that were included in the survey questionnaires.

The personal contacts and interviews with experts in the field turned out to be a valuable source that rendered rich information. It also often had a knock-on effect that lead to interviews with further experts mentioned by some of the interviewees, or to experts being willing to complete the questionnaires once they had been prompted to do so in the interview situation.

\section{- Method 4: Desktop search}

Since a substantial amount of information related to the main themes of this study are available on publicly accessible websites, desktop searches were done on relevant websites of institutions (such as universities and non-profit organizations) to gather information regarding training, teaching and research in Business and Economic Ethics offered by individuals and institutions.

The desktop search turned out to be a valuable method of data collection in a number of countries since it was the only source of available information. However, the desktop searches were hampered by two problems. The first was the high cost, unavailability or unreliability of internet access in certain countries in the Global South. The second was the fact that many institutional websites were poorly developed with scant information and often without a search function to find information related to Business and Economic Ethics.

\section{- Method 5: Database analysis}

Where databases that captured information about training, teaching or research in the field of Business and Economic Ethics were available, such databases were analysed to extract the required information.

Database analyses were particularly helpful in gathering data about publications in the field of Business and Economic Ethics. A problem was encountered to link publications to the country of origin of their authors. A solution was eventually found in the form of some databases that do indicate the institutional affiliation of authors. These institutions were then manually matched with specific countries to compile a regional database of publications for each region. Databases that were particularly valuable were the ISI, Scopus, and World of Learning databases.

The information gathered through the above mentioned research methods was collated, analysed and then integrated in the regional reports. In what follows, the findings of the Global Survey of Business Ethics for each of the eight world regions are first presented separately and finally compared across the eight world regions in the concluding article.

\section{References}

Chan, K. C., Fung, H.-G., \& Yau, J. (2010). Business Ethics research: A global perspective. Journal of Business Ethics, 95, 39-53.

Cowton, C. J., \& Dunfee, T. W. (1995). Internationalizing the Business Ethics curriculum: A survey. Journal of Business Ethics, 14(5), 331-338.

De George, R. T. (1987). The status of business ethics: Past and future. Journal of Business Ethics, 6, 201-211.

Enderle, G. (1996). A comparison of business ethics in North America and Continental Europe. Business Ethics: A European Review, 5(1), 33-46.

Enderle, G. (1997). A worldwide survey of business ethics in the 1990s. Journal of Business Ethics, 16(14), 1475-1483.

Van Luijk, H. J. L. (1990). Recent developments in European business ethics. Journal of Business Ethics, 9, 537-544.

Werhane, P. H., \& Freeman, R. E. (Eds.). (1997). The Blackwell encyclopedic dictionary of business ethics. Oxford: Blackwell.

Werhane, P. H., \& Freeman, R. E. (Eds.). (2005). Business ethics, vol. 2 of the Blackwell encyclopedia of management. Oxford: Blackwell. 